\title{
Refractory Spinal Cord Neoplasm
}

National Cancer Institute

\section{Source}

National Cancer Institute. Refractory Spinal Cord Neoplasm. NCI Thesaurus. Code C71703.

Spinal cord neoplasm resistant to treatment. 